\title{
Interkingdom interaction between $C$. albicans and S. salivarius on titanium surfaces
}

\author{
Loyse Martorano-Fernandes ${ }^{10}$, Nadiny Cezar Rodrigues ${ }^{2}$ (i), Maria Heloísa de Souza Borges² (1), \\ Yuri Wanderley Cavalcanti ${ }^{3}$ (I) and Leopoldina de Fátima Dantas de Almeida ${ }^{3^{*}}$ (1)
}

\begin{abstract}
Background: In oral candidiasis models, Candida albicans and Streptococcus salivarius sp. biofilms have an antagonistic relationship. Due to this, S. salivarius have been used experimentally as probiotic. However, the interaction between these microorganisms in the peri-implantitis-like microenvironment remains unknown. This study aimed to evaluate the interaction between C. albicans and S. salivarius biofilms developed on titanium surfaces, under reduced oxygen levels.

Methods: Titanium specimens were pre-conditioned with artificial saliva $\left(1 \mathrm{~h}, 37^{\circ} \mathrm{C}\right)$. Single-species biofilms of $C$. albicans (ATCC 90028) and co-culture biofilms of C. albicans and S. salivarius (ATCC 7073) was developed for 24 and $72 \mathrm{~h}$ on titanium specimens. Subsequently, the effect of these intervals of biofilm formation and the interactions among the cells were evaluated. Biofilms from cultures were collected and analyzed for cell viability (CFU/mL), biofilm biomass, and total protein dosage. Data were analyzed using Mann-Whitney test $(a=5 \%)$. In addition, co-culture biofilms were analyzed using fluorescence microscopy.
\end{abstract}

Results: C. albicans growth did not change due to the presence of S. salivarius. Besides, co-culture biofilms showed a significant difference in the number of viable cells between 24 and $72 \mathrm{~h}$ of biofilm development $(p<0.05)$. The highest biofilm biomass and protein dosage were observed in co-cultures at $72 \mathrm{~h}$ of biofilm development. Fluorescence microscopy showed that co-cultures biofilms at $24 \mathrm{~h}$ have limited number of pseudo-hyphal and hyphae cells of $C$. albicans. At $72 \mathrm{~h}$, these types of cells have increased. S. salivarius in both stages of development was present in some clusters surrounded by C. albicans.

Conclusions: Co-cultivation of C. albicans with S. salivarius in biofilms developed on titanium surfaces, under lower oxygen levels, did not affect fungus growth. In addition, S. salivarius did not hind C. albicans virulence. These findings suggest that the use of $S$. salivarius as a probiotic would be ineffective in peri-implant disease treatment.

Keywords: Peri-implantitis, Candida albicans, Streptococcus salivarius

\section{Background}

Prostheses supported by titanium dental implants are commonly used for the rehabilitation of total and partially edentulous patients [1]. However, approximately $22-43 \%$ of cases develop inflammatory diseases called

\footnotetext{
*Correspondence: leopoldinalmeida@hotmail.com

${ }^{3}$ Department of Clinic and Social Dentistry, Federal University of Paraíba,

Cidade Universitária, João Pessoa, Paraiba, Brazil

Full list of author information is available at the end of the article
}

peri-implant mucositis and peri-implantitis, which occur mainly due to the presence of biofilm [2]. These diseases begin when microorganisms interact with each other, attach on the titanium implant surface and proliferate, reaching a mature biofilm capable to invade the tissue and induce an inflammatory process in the host [3]. In advanced stages of those diseases, the bone around the implant reabsorb, which can result in the loss of the dental implant [4-6]. Thereby, understanding the biofilm 
formation and the microorganism's interactions could create targeted approaches to pathogen control.

The peri-implant biofilm is mostly composed of Candida albicans $[7,8]$, which has the ability to form robust mixed biofilms and invade tissues $[9,10]$. In the periimplant region, C. albicans establishes interactions with Streptococcus species, which can benefit (synergism relationship) or inhibit (antagonism relationship) the fungal growth, modulating the potential of $C$. albicans to cause diseases [10]. In an oral candidiasis model, a known antagonism relationship occurs between C. albicans and Streptococcus salivarius, through a metabolic product known as bacteriocin-like inhibitory substances (BLIS). This metabolic is released extracellularly by the bacteria and can kill or interfere with the growth of pathogenic microorganisms $[11,12]$. Due to this mechanism of action, S. salivarius may be used experimentally as probiotic to treat oral candidiasis $[11,13]$.

However, the relationship between $C$. albicans and $S$. salivarius under peri-implantitis-like microenvironment is still unclear. Therefore, the purpose of this in vitro study was to evaluate the interaction between $C$. albicans and S. salivarius biofilms developed on titanium surfaces, under reduced oxygen levels. To understand this interaction, single-species biofilms of $C$. albicans, single-species biofilms of $S$. salivarius and co-cultures of C. albicans and $S$. salivarius were developed on the surface of preconditioned titanium specimens. After $24 \mathrm{~h}$ and $72 \mathrm{~h}$, the biofilms were analyzed regarding cell viability, biomass quantification, and total protein dosage. Altogether, our results suggest that $C$. albicans $-S$. salivarius interactions under peri-implant environment might be different from other oral conditions; and these findings showed new directions regarding the treatment of the periimplant disease.

\section{Methods}

\section{Specimens' preparation}

Standardized discs of commercially pure titanium $(1.3 \times 0.2 \mathrm{~cm})$ were prepared according to with previously methodologies [14]. The specimens did not have any treatment on their surface. Therefore, there was not any antimicrobial activity or potential to inhibit the biofilm formation. The titanium discs were cleaned with $70 \%$ alcohol (v/v) and sterilized by autoclave at $121{ }^{\circ} \mathrm{C}$ for 15 min prior to use.

\section{Microbial strains and growth conditions}

C. albicans (ATCC 90028) and S. salivarius (ATCC 7073) were used to generate single-species and co-culture biofilms. These strains were reactivated aerobically from their original cultures in Agar Sabouraud Dextrose (Difco, Detroit, USA) and Brain Heart Infusion (Kasvi,
Italy) at $37^{\circ} \mathrm{C}$, respectively. The yields of microorganisms were analyzed by seeding bacterial and fungi suspension into agar plates. Therefore, the concentration of microorganisms was based on CFU/mL quantification. Three to five colonies of each strain were collected and suspended in $5 \mathrm{~mL}$ of sterile saline $(0.9 \% \mathrm{NaCl})$. Then, cells were centrifuged (5000 g for $5 \mathrm{~min}$ ), washed twice with saline, and suspended in RPMI 1640 medium (Inlab diagnóstica, Brazil) to standardize concentrations. The concentration of C. albicans at $\mathrm{OD}_{600}$ was $1.0 \times 10^{6} \mathrm{CFU} / \mathrm{mL}$, whilst the concentration of $S$. salivarius was $1.0 \times 10^{8} \mathrm{CFU} / \mathrm{mL}$ (LGL Scientific 0741/16, Brazil). These concentrations were based on experiments described previously [14, 15]. RPMI 1640 was used because has the nutritional requirements of both microorganisms $[16,17]$.

\section{Preconditioning with artificial saliva and biofilm development}

Initially, titanium discs were immersed in $500 \mu \mathrm{L}$ of artificial saliva composed of $1 \%$ carboxymethyl (w/v); $0.0084 \%$ sodium chloride $(\mathrm{w} / \mathrm{v}) ; 0.12 \%$ potassium chloride $(\mathrm{w} / \mathrm{v}) ; 0.0342 \%$ potassium phosphate $(\mathrm{w} / \mathrm{v}) ; 0.0146 \%$ calcium chloride $(\mathrm{w} / \mathrm{v})$, and $0.052 \%$ magnesium chloride $(\mathrm{w} / \mathrm{v})[18,19]$; following by incubation at $37^{\circ} \mathrm{C}$ for 60 min [20]. Subsequently, the specimens were randomly and individually allocated into 24-well plates. For singlespecies biofilms, each titanium disc was inoculated with C. albicans or S. salivarius. For co-culture biofilms, both C. albicans and S. salivarius were added to the inoculum. The plates were incubated at $37^{\circ} \mathrm{C}$ under a microaerobic atmosphere using an anaerobic jar with a candle, which reduced the presence of oxygen, similar to a periimplantitis-like microenvironment [20]. The culture medium was changed daily until the end of the experimental period $(72 \mathrm{~h})$. The development of each biofilm was assessed at $24 \mathrm{~h}$ (mature biofilm) and $72 \mathrm{~h}$ (biofilm dispersion stage). Biofilms were analyzed with regards the number of colony-forming units $(\mathrm{CFU} / \mathrm{mL})$, biomass quantification, and total protein dosage. The experiments were performed independently in duplicate $(n=12 /$ group).

\section{Cell viability analysis}

After $24 \mathrm{~h}$ and $72 \mathrm{~h}$, specimens were transferred to microtubes containing $1.0 \mathrm{~mL}$ of sterile saline and agitated in a vortex for $60 \mathrm{~s}$ [20]. Subsequently, the suspensions were serially diluted to determine the number of viable microorganisms $\left(10^{-1}\right.$ to $\left.10^{-6}\right)$. Aliquots of $10 \mu \mathrm{L}$ from each dilution were seeded in Sabouraud Dextrose Agar (SDA) and Mitis Salivarius Agar (MSA). The plates incubated at $37{ }^{\circ} \mathrm{C}$ for $24 \mathrm{~h}$. The number of viable cells was determined after counting colony-forming units. 
The values were multiplied by the serial dilution and converted to a logarithmic scale, expressed in CFU $/ \mathrm{mL}$.

\section{Biomass quantification}

The biofilms' biomass quantification was performed using the crystal violet assay [21]. Culture medium was removed from the plates and the discs were dried for $45 \mathrm{~min}$ at $37^{\circ} \mathrm{C}$. Afterwards, $600 \mu \mathrm{L}$ of crystal violet aqueous solution (Labsynth Produtos para Laboratório LTDA, Diadema, Brazil) at $0.5 \%(\mathrm{w} / \mathrm{v})$ was added on discs for $30 \mathrm{~min}$. The solution was removed and washed three times with sterile saline. Subsequently, $600 \mu \mathrm{L}$ of $70 \%$ acetic acid $(\mathrm{v} / \mathrm{v})$ was added. The supernatant was read using spectrophotometry at $590 \mathrm{~nm}$.

\section{Total protein dosage}

The measurement of total proteins was performed according to the biuret assay [22], using a commercial diagnostic kit for total proteins (Labtest, Minas Gerais, Brazil). The calibration solution used had $4 \mathrm{~g} / \mathrm{dL}$ bovine albumin and $14.6 \mathrm{mmol} / \mathrm{L}$ sodium azide. Initially, the culture medium was removed from the plates and the discs washed with $500 \mu \mathrm{L}$ of sterile saline. The solution was centrifuged ( $5000 \mathrm{~g}$ for $5 \mathrm{~min}$ ) and added $500 \mu \mathrm{L}$ of $1 \mathrm{M} \mathrm{NaOH}$. After that, the samples were vortexed and centrifuged for $10 \mathrm{~s}$. For cell lysis, $1.0 \mathrm{~mL}$ of biuret reagent was added. The samples were incubated for $10 \mathrm{~min}$ at $37^{\circ} \mathrm{C}$. Afterwards, the absorbance of samples was read in a spectrophotometer at $495 \mathrm{~nm}$. Based on the obtained data, the total protein was calculated considering the sample absorbance by the calibration factor.

\section{Fluorescence microscopy}

Co-culture biofilms developed during $24 \mathrm{~h}$ and $72 \mathrm{~h}$ were analyzed descriptively using fluorescence microscopy (Leica Microsystems GmbH, Wetzlar, Germany). Representative images were generated to assess interactions between bacteria and fungi, as well as the $C$. albicans cell types (yeast-form cells, oval pseudo-hyphal cells, and elongated hyphal cells) [14]. Previously the analysis, biofilms were fixed with $10 \%(\mathrm{v} / \mathrm{v})$ formal-saline for $48 \mathrm{~h}$ at $4{ }^{\circ} \mathrm{C}$. The samples were then stained with $10 \mu \mathrm{L}$ of propidium iodide ( $25 \mu \mathrm{M}$; Molecular Probes, Paisley, UK) to stain S. salivarius and $10 \mu \mathrm{L}$ of calcofluor white $(1 \%(\mathrm{v} / \mathrm{v})$; Sigma-Aldrich) to stain C. albicans [14]. Representative images $(100 \mu \mathrm{m} \times 100 \mu \mathrm{m})$ of both dye-channels were obtained from five different fields of view. C. albicans morphotypes analysis was based on previous investigations parameters [14].

\section{Statistical analysis}

The Statistical Package for Social Sciences (SPSS) software (SPSS, IBM, Chicago, IL, USA) was used for data analysis. Data were analyzed with regards their normality (ShapiroWilk test) and homoscedasticity (Levene test). Statistical analysis was performed using Mann-Whitney test with $5 \%$ significance $(\alpha<0.05)$ and minimal power of $80 \%$. In all experiments, two statistical analyses were performed. Firstly, the development stage of biofilm was considered the comparison factor. Mature $(24 \mathrm{~h})$ and dispersion stage $(72 \mathrm{~h}$ ) biofilms were compared to understand the effect of these time intervals on biofilm formation. Then, second analysis compared the biofilm type (sigle-species or co-culture) to comprehend the meaning of interactions among the cells within the same interval ( $24 \mathrm{~h}$ or $72 \mathrm{~h})$.

\section{Results}

Single-species and co-culture biofilms of $C$. albicans presented higher number of viable cells within $24 \mathrm{~h}$ and $72 \mathrm{~h}$ compared to those of $S$. salivarius. Overall, single-species biofilms of both species did not change significantly between 24 and $72 \mathrm{~h}$. In contrast, co-culture biofilms showed a significant difference between 24 and $72 \mathrm{~h}$ of biofilm development $(p<0.05)$ (Fig. 1a).

To better understand the effect of cell physical contact between $C$. albicans and $S$. salivarius we evaluated the cell viability of each biofilm type. Interestingly, C. albicans did not have its viability changed in single-species and co-culture biofilms. On the other hand, the higher number of viable cells of $S$. salivarius was detected in co-culture biofilms at $24 \mathrm{~h}$. Moreover, the growth of $S$. salivarius at $24 \mathrm{~h}$ was significantly different between single-species and co-culture biofilms $(p<0.05)$ (Fig. 1b).

Regarding the biofilm biomass, co-culture biofilms presented higher amounts of cells at $72 \mathrm{~h}$. Although this happened, it was not enough to be significant, as long as single-species biofilms of $C$. albicans and $S$. salivarius showed a significant difference between 24 and $72 \mathrm{~h}$ of biofilm development, compared to co-culture biofilms $(p<0.05)$ (Fig. 2a). Overall, single-species and coculture biofilms of $C$. albicans and $S$. salivarius did not show a significant difference in biofilm biomass $(p>0.05)$ (Fig. 2b).

With regards the total protein production, higher amount of proteins occurred at $72 \mathrm{~h}$ of biofilm development for single-species and co-culture biofilms. Singlespecies biofilms of $S$. salivarius presented significantly higher concentration of total protein $(p<0.05)$. Co-culture biofilms also demonstrated a statistically significant difference between 24 and $72 \mathrm{~h}(p<0.05)$ (Fig. 3a). Single-species biofilms of $S$. salivarius presents statistically lower quantity of total protein compared to that observed in co-culture biofilms $(p<0.05)$ (Fig. 3b).

Fluorescence microscopy has shown that co-cultures biofilms at $24 \mathrm{~h}$ presented higher amounts of yeast-form 

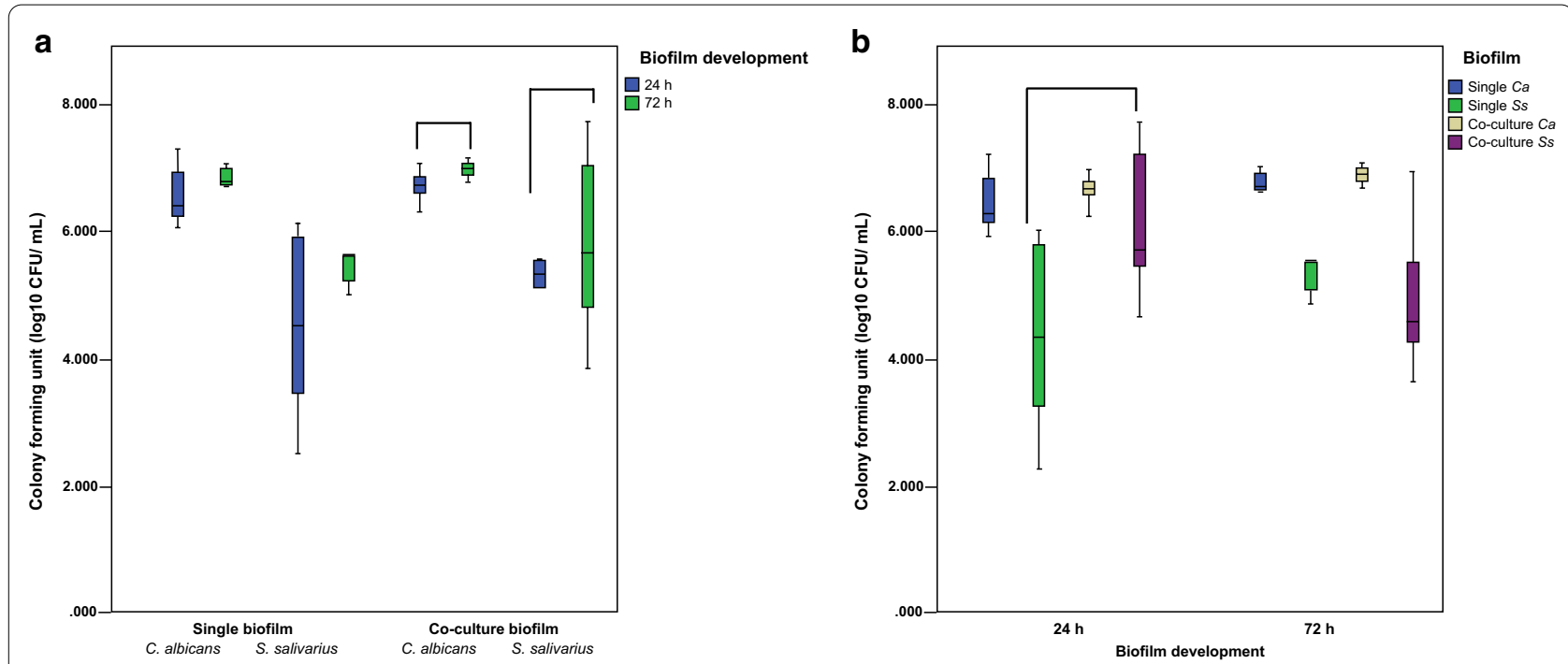

Fig. 1 Cell viability of single-species and co-culture biofilms $(n=12)$. a Development stage of biofilms at $24 \mathrm{~h}$ and $72 \mathrm{~h}$. Co-culture biofilms of C. albicans and S. salivarius showed a statistically significant difference between 24 and $72 \mathrm{~h}$ of biofilm development compared to single-species biofilms $(p<0.05)$. Connected groups present a statistical difference (Mann-Whitney, $p<0.05$ ). Data shown are from box-plot: each box contains $50 \%$ of the group data; the lower and upper limits represent the 25 th and 75 th percentiles, respectively; bars represent the minimum and maximum values, and the horizontal line inside the box represents median. b Biofilm types (single-species or co-culture biofilms) within the same time interval ( $24 \mathrm{~h}$ or $72 \mathrm{~h}$ ). Cell viability of S. salivarius at $24 \mathrm{~h}$ differed statistically between single-species and co-culture biofilms. ( $p<0.05)$. Connected groups present a statistical difference (Mann-Whitney, $p<0.05$ ). Data shown are from the box-plot: each box contains 50\% of the group data; the lower and upper limits represent the 25th and 75th percentiles, respectively; bars represent the minimum and maximum values, and the horizontal line inside the box represents median
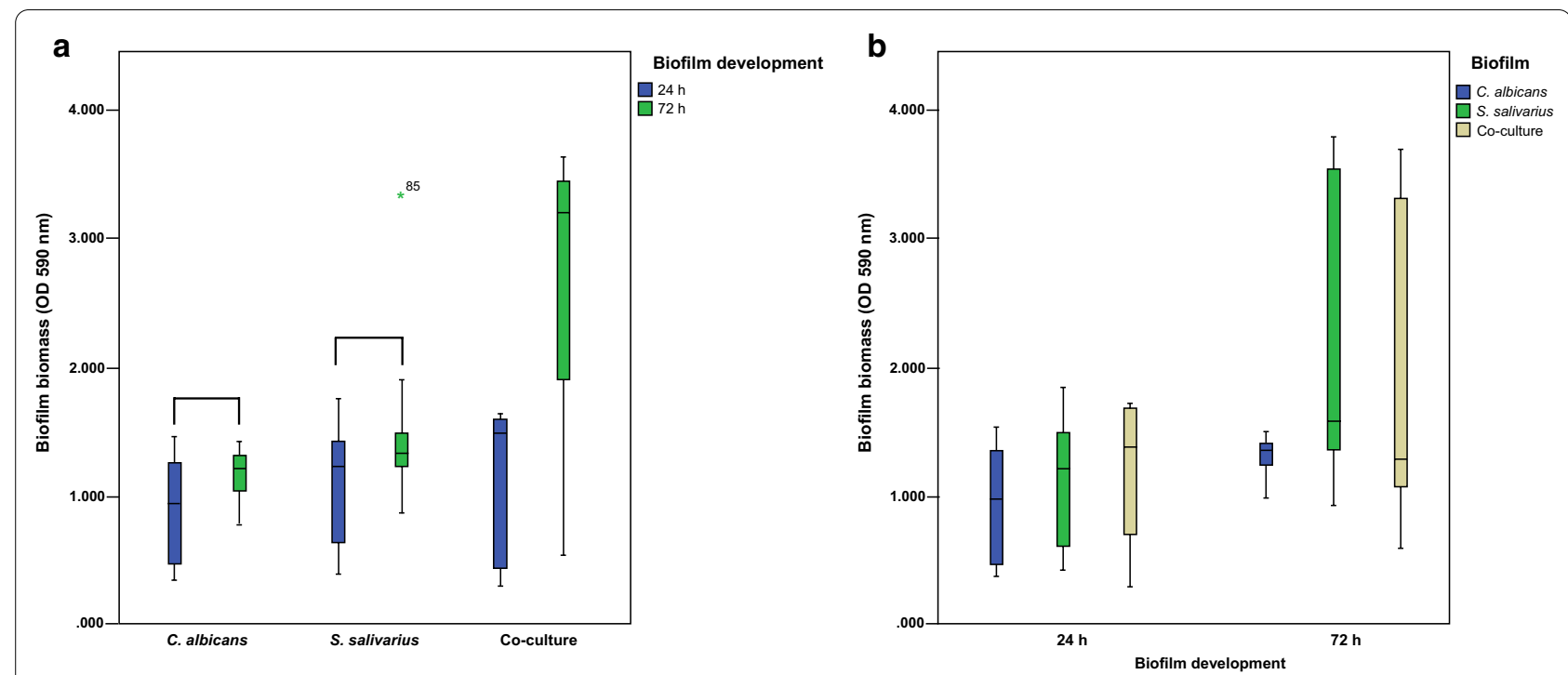

Fig. 2 Biofilm biomass of single-species and co-culture biofilms $(n=12)$. a Development stage of biofilms at $24 \mathrm{~h}$ and $72 \mathrm{~h}$. Single-species biofilms of C. albicans and S. salivarius showed statistically significant difference compared to co-culture biofilms at $24 \mathrm{~h}$ and $72 \mathrm{~h}(p<0.05)$. Connected groups present a statistical difference (Mann-Whitney, $p<0.05$ ). Data shown are from box-plot: each box contains $50 \%$ of the group data; the lower and upper limits represent the 25th and 75th percentiles, respectively; bars represent the minimum and maximum values, and the horizontal line inside the box represents median. b Biofilm types (single-species or co-culture) within the same time interval ( $24 \mathrm{~h}$ or $72 \mathrm{~h}$ ). The groups did not differ statistically $(p>0.05)$. Connected groups present a statistical difference (Mann-Whitney, $p<0.05)$. Data shown are from the box-plot: each box contains 50\% of the group data; the lower and upper limits represent the 25 th and 75 th percentiles, respectively; bars represent the minimum and maximum values, and the horizontal line inside the box represents median 


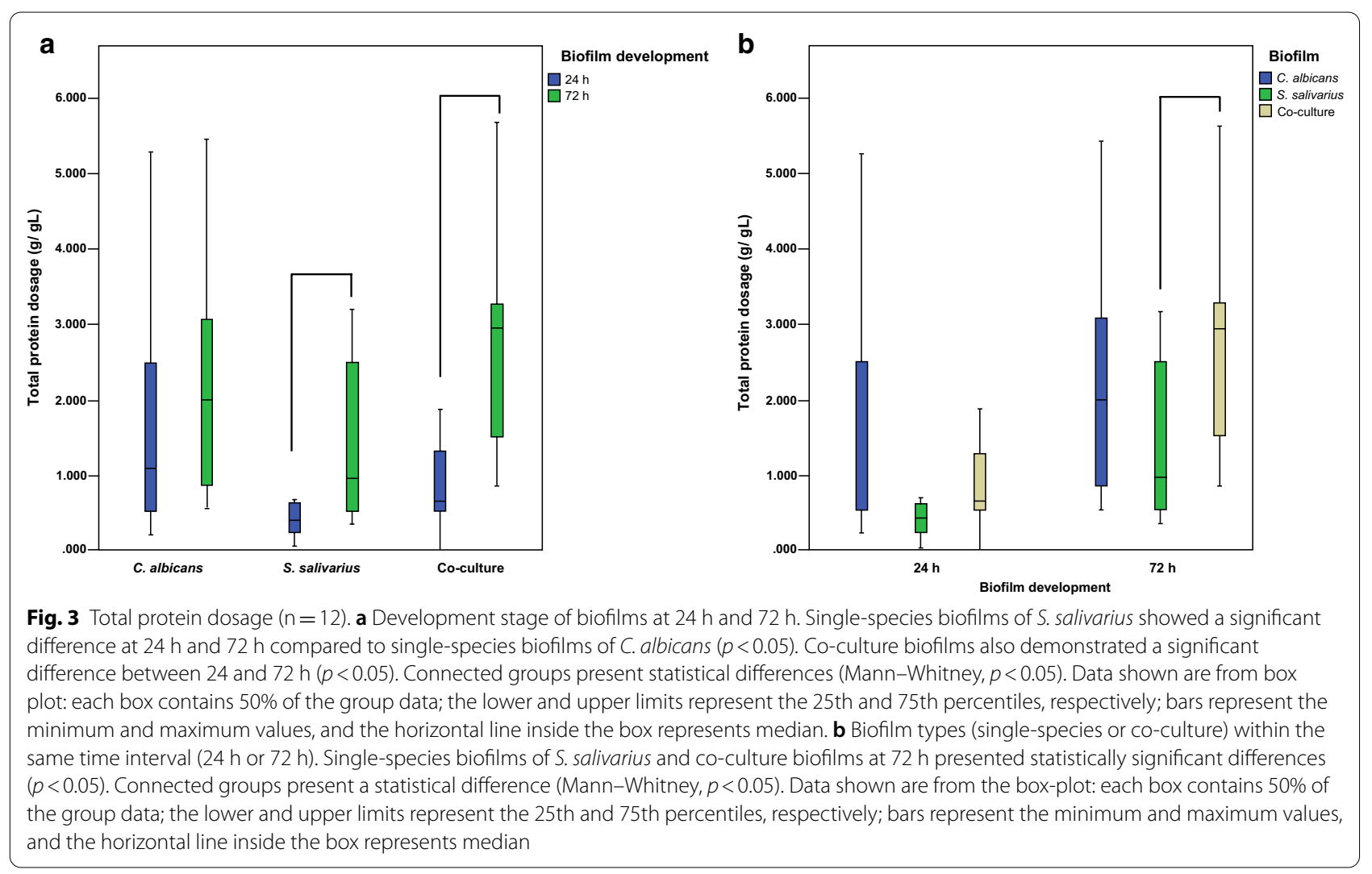

cells surrounded by limited pseudo-hyphal cells and hyphae (Fig. 4a). On the other hand, co-cultures biofilms at $72 \mathrm{~h}$ showed numerous pseudo-hyphal cells and some hyphae (Fig. 4b). S. salivarius cells at $24 \mathrm{~h}$ and $72 \mathrm{~h}$ of biofilm formation are presented in some clusters around the fungi (Fig. 4a, b).
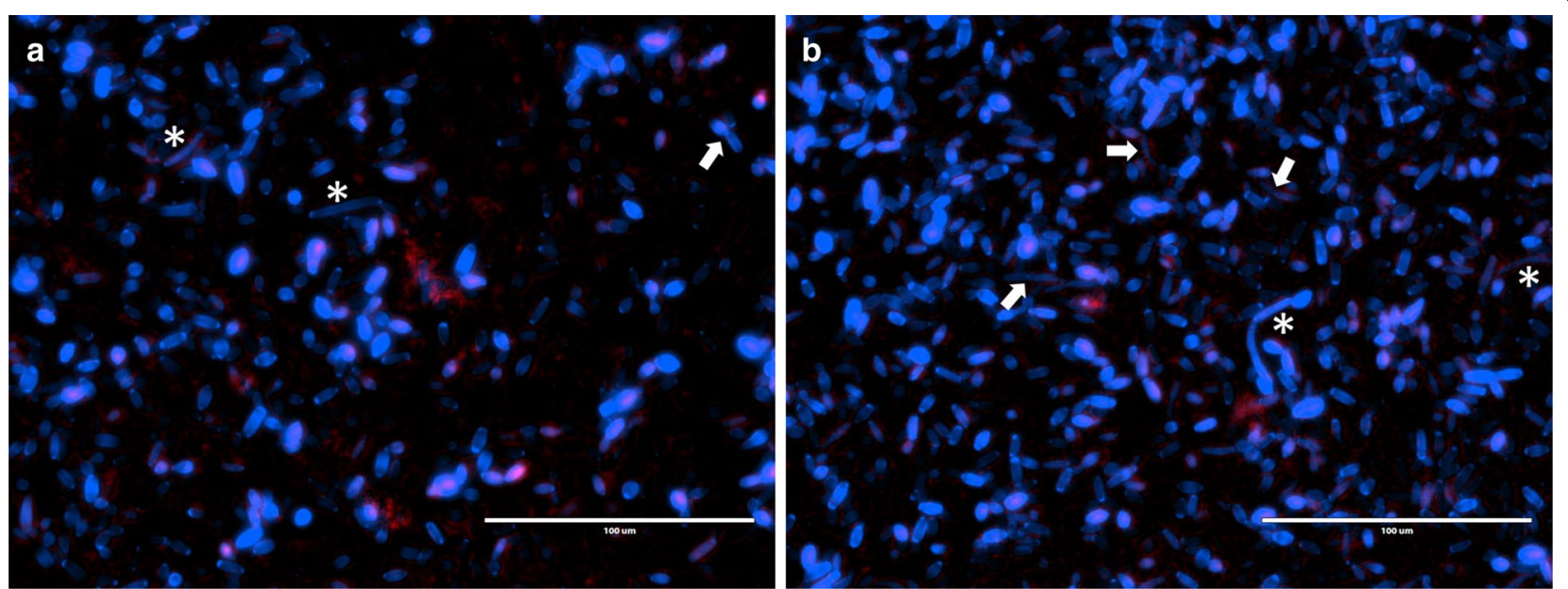

Fig. 4 Representative images of fluorescence microscopy of co-culture biofilms of C. albicans and S. salivarius developed under peri-implantitis-like microenvironment conditions. C. albicans is stained with calcofluor white (blue) and S. salivarius is stained with propidium iodide (red). Arrows demonstrate C. albicans pseudo-hyphal, whilst * shows hyphae cells. a Co-culture biofilms at $24 \mathrm{~h}$. Note limited pseudo-hyphal cells and hyphae surrounded by clusters of bacteria. b Fungi-bacteria biofilm developed at $72 \mathrm{~h}$. Note numerous pseudo-hyphal cells and some hyphae. Also, the presence of bacteria agglomerates 


\section{Discussion}

Mucositis and peri-implantitis are infections caused by fungi and bacteria biofilms [23-25]. Understanding this biofilm is essential to guide future therapeutic approaches, such as the use of probiotics. Traditionally, in oral candidiasis models, C. albicans and S. salivarius establish antagonistic relationships, in which the fungal cells are surrounded by $S$. salivarius, resulting in a decrease adhesive of ability and pathogenic potential $[11,13]$. Thus, S. salivarius may be used as an alternative to the treatment of oral candidiasis. However, our findings suggest the antagonistic relationship C. albicans and S. salivarius was not established within the peri-implant microenvironment, in which biofilms were developed on titanium surfaces under low oxygen levels. Therefore, the use of $S$. salivarius as a probiotic would not be effective in treating peri-implant diseases.

Previous studies demonstrated an antagonistic interaction between $C$. albicans and S. salivarius using the following bacteria strains SK56, DSM14685, and K12 [11, 13, 26-28]. In our study, S. salivarius ATCC 7073 was used in all experiments. Evidence shows that the $S$. salivarius NCTC 8618 strain, which is a homologous strain of ATCC 7073 (available from https://www.atcc. org/Products/All/7073.aspx\#generalinformation) also develops an antagonism relationship with $C$. albicans tested in vitro and in vivo [29]. These findings reinforce that an antagonistic relationship would be expected between $S$. salivarius and C. albicans. Of importance, $S$. salivarius is recognized as a microorganism that does not cause harmful effects on humans and plays an important role in the biofilm composition, by inactivating and establishing antagonistic relationships with oral pathogens, such as Candida albicans [11, 13]. Thus, according to our findings, we suggest the antagonistic relationships did not happen due to the conditions in which biofilms were developed.

In the oral cavity, the oxygen levels, the substratum (e.g. mucosa, teeth, prosthesis, and implants), and variations in nutrient content could hind microorganisms to establish interactions [30]. Our study used RPMI 1640 medium, which is known to mimic the composition of human fluids, due to the presence of amino acids such as L-Glutamine, L-Arginine, and L-Asparagine, as well as vitamins and inorganic salts [31]. Previous investigations showed that RPMI 1640 medium can be used to initiate and develop in vitro biofilms of $C$. albicans, similarly to yeast nitrogen base and sabouraud dextrose broth medium [16]. Regarding the bacteria growth, RPMI 1640 has the nutritional requirements of S. salivarius [17]. Therefore, RPMI 1640 medium does not hind interactions between the microorganisms tested in this study.
Regarding the cell viability, co-culture biofilms of C. albicans showed differences between 24 and $72 \mathrm{~h}$ of biofilm development, in which the higher viability was at $72 \mathrm{~h}$. Moreover, C. albicans did not have its viability changed in single-species and co-culture biofilms. This data suggested that, under the conditions tested in this study, S. salivarius was unable to decrease the number of fungal cells. Observations of C. albicans growth indicate that the mature and dispersion stage is mostly composed of cells in a hyphae-form, which are related to virulence and pathogenicity of Candida biofilms [32]. At these stages, the dispute for nutrients among the cells may be so high that the bacteria can not interfere with the fungus growth. Although this occurs, the viability of the bacteria has not been disabled. Co-cultures biofilms of S. salivarius presented significantly higher number of viable cells.

Interactions between fungi and bacteria occur through physical contact or metabolic products [33-35]. S. salivarius can interact with other microorganisms through its bacteriocin-like inhibitory substances (BLIS), which is responsible for maintaining orderly population dynamics within oral microbiota [36]. Although there is a lack of evidence concerning bacteriocin production of the strain S. salivarius ATCC 7073, the bacteriocin production has been reported in several $S$. salivarius strains [36-38]. Thus, it might be possible that S. salivarius ATCC 7073 also produced bacteriocins because it is a behavior characteristic of the streptococcal species. Notwithstanding, future studies should evaluate the $S$. salivarius ATCC 7073 bacteriocin production.

Despite BLIS contribution to interactions among the microorganisms in an oral candidiasis model, C. albicans was not directly inhibited by bacteriocin action. Indeed, physical cell contact is required to inhibit fungi's growth [11]. These findings suggest that the ability of S. salivarius inactivating some microorganisms is apart from the bacteriocin's action. Another explanation for S. salivarius did not decreasing $C$. albicans development is the time in which BLIS operates. Usually, microorganisms' metabolite products act during the early stages of biofilm development, especially during exponential growth $[13,39]$. It is possible that at the times evaluated in this study, the metabolite product was inactive, being insufficient to decrease the $C$. albicans growth. Thereby, future studies should evaluate the biofilm at the early stages of development.

In addition, the exponential growth of the $C$. albicans biofilm continues to advance in its maturation stage, resulting in several dense layers of polymorphic cells round in an extracellular matrix. This matrix gives the biofilm a robust and dense structure, which could protect it from chemical and physical injury $[40,41]$. One possibility to estimate the contribution of the biofilm's matrix 
is by measuring the biomass of the biofilm. Expectedly, single-species biofilms of $C$. albicans have significantly higher biomass at $72 \mathrm{~h}$ compared to $24 \mathrm{~h}$. Besides that, our results indicate that co-culture biofilms at $72 \mathrm{~h}$ presented higher biomass. These findings suggest that the matrix of biofilm contributes to its architecture and could act as a protective barrier for $C$. albicans.

The extracellular matrix of biofilm has around 500 proteins in its structure, most of which are hydrolyzing enzymes that can disrupt biopolymers as both a protective response and a nutrient source [40]. Preliminarily, we also investigate the proteins in the biofilm cultures throughout the biuret assay. Higher protein production was observed at $72 \mathrm{~h}$ of biofilm development, and this is possibly due to the longer period these biofilms remained in cultivation. Moreover, there is possible that a fungibacteria relationship and a robust extracellular matrix contributed to increasing the total protein production. However, our results are limited to the dosage of total proteins, which could not estimate which protein would make the greatest contribution to this biofilm. The process of identifying this protein could be important for creating therapeutic targets.

In general, our findings suggest that $C$. albicans growth did not change due to the presence of $S$. salivarius. To better understand the interactions between both microorganisms and the virulence of $C$. albicans through the filamentous formation, fluorescence microscopy was performed. In the early stage $(24 \mathrm{~h})$, the yeast cells were prevalent, with few pseudo-hyphal cells and hyphae surrounded by $S$. salivarius. However, at $72 \mathrm{~h}$ numerous pseudo-hyphal cells and some hyphae were presented. The filamentous forms of $C$. albicans (hyphae and pseudo-hyphae) are considered pathogenic [42]. Thus, these results suggest that under the conditions tested in this study and during the dispersion stage, $C$. albicans inactivation is a challenge to $S$. salivarius.

Although microscopy evaluations are widely used, future investigations should consider using gene expression analysis or other genetic approaches to evaluate transcriptional regulators of C. albicans (Efg1, Tec1, Bcr1, Ndt80, Brg1, and Rob1) [40], virulence factors such as Hwp1 and Als3 [40], as well as invasiveness (Sap family) [43]. In addition, other study designs should consider including relevant bacteria involved with peri-implant infections (i.e. Porphyromonas gingivalis) [8] and hostpathogen interactions of C. albicans [23].

\section{Conclusions}

Overall, we observed that C. albicans development follows its course in phases of development independently of S. salivarius. Although S. salivarius is a facultative anaerobe, surprisingly, on titanium surfaces and under lower oxygen, the bacterium was not able to inactivate fungal growth. Moreover, at the dispersion stage, C. albicans increase their virulence. Therefore, this interaction in the peri-implant environment could be a challenge to S. salivarius act as an antagonist microorganism.

\section{Abbreviations}

ATCC: American type culture collection; CFU/mL: Colony-forming units per milliliter; SDA: Sabouraud dextrose agar; MSA: Mitis salivarius agar; SPSS: Statistical package for social sciences.

\section{Acknowledgements}

Not applicable.

\section{Authors' contributions}

LMF, YWC and LFDA designed the study. LMF, NCR and MHSB performed experiments and collected data. LMF, YWC and LFDA analyzed and interpreted data. LMF, NCR and MHSB drafted the manuscript. YWC and LFDA supervised the research and revised the manuscript for important intellectual content. All authors read and approved the final manuscript.

\section{Funding}

The authors would like to thank you the Conselho Nacional de Desenvolvimento Científico e Tecnológico_Brasil (CNPq)—for the scholarship provided to the first author.

\section{Availability of data and materials}

The datasets used and/or analyzed during the current study are available from the corresponding author on reasonable request.

Ethics approval and consent to participate

Not applicable.

\section{Consent for publication}

Not applicable.

\section{Competing interests}

The authors declare that they have no competing interests.

\section{Author details}

${ }_{1}^{1}$ Postgraduate Program in Dentistry, Federal University of Paraíba, Cidade Universitária, João Pessoa, Paraiba, Brazil. ${ }^{2}$ School of Dentistry, Federal University of Paraíba, Cidade Universitária, João Pessoa, Paraiba, Brazil. ${ }^{3}$ Department of Clinic and Social Dentistry, Federal University of Paraíba, Cidade Universitária, João Pessoa, Paraiba, Brazil.

Received: 13 May 2020 Accepted: 17 November 2020

Published online: 01 December 2020

References

1. Kim HS, Cho HA, Kim YY, Shin H. Implant survival and patient satisfaction in completely edentulous patients with immediate placement of implants: a retrospective study. BMC Oral Health. 2018;18(1):219. https:// doi.org/10.1186/s12903-018-0669-1.

2. Derks J, Tomasi C. Peri-implant health and disease. A systematic review of current epidemiology. J Clin Periodontol. 2015;42(Suppl 16):S158-71. https://doi.org/10.1111/jcpe.12334.

3. Salvi GE, Cosgarea R, Sculean A. Prevalence and mechanisms of peri-implant diseases. J Dent Res. 2017;96(1):31-7. https://doi. org/10.1177/0022034516667484.

4. Daubert DM, Weinstein BF. Biofilm as a risk factor in implant treatment. Periodontol 2000. 2019;81(1):29-40. https://doi.org/10.1111/prd.12280.

5. Lee CT, Huang YW, Zhu L, Weltman R. Prevalences of peri-implantitis and peri-implant mucositis: systematic review and meta-analysis. J Dent. 2017;62:1-12. https://doi.org/10.1016/j.jdent.2017.04.011. 
6. Sgolastra F, Petrucci A, Severino M, Gatto R, Monaco A. Periodontitis, implant loss and peri-implantitis. A meta-analysis. Clin Oral Implants Res. 2015;26(4):e8-16. https://doi.org/10.1111/clr.12319.

7. Schwarz F, Becker K, Rahn S, Hegewald A, Pfeffer K, Henrich B. Real-time PCR analysis of fungal organisms and bacterial species at peri-implantitis sites. Int J Implant Dent. 2015;1(1):9.

8. Lafaurie Gl, Sabogal MA, Castillo DM, Rincón MV, Gómez LA, Lesmes YA, Chambrone L. Microbiome and microbial biofilm profiles of peri-implantitis: a systematic review. J Periodontol. 2017;88(10):1066-89. https://doi. org/10.1902/jop.2017.170123.

9. Rickard AH, Gilbert P, High NJ, Kolenbrander PE, Handley PS. Bacterial coaggregation: an integral process in the development of multi-species biofilms. Trends Microbiol. 2003;11(2):94-100.

10. Peleg AY, Hogan DA, Mylonakis E. Medically important bacterial-fungal interactions. Nat Rev Microbiol. 2010;8(5):340-9. https://doi.org/10.1038/ nrmicro2313.

11. Ishijima SA, Hayama K, Burton JP, Reid G, Okada M, Matsushita Y, Abe S. Effect of Streptococcus salivarius K12 on the in vitro growth of Candida albicans and its protective effect in an oral candidiasis model. Appl Environ Microbiol. 2012;78(7):2190-9. https://doi.org/10.1128/AEM.07055-11.

12. Zupancic K, Kriksic V, Kovacevic I, Kovacevic D. Influence of oral probiotic Streptococcus salivarius K12 on ear and oral cavity health in humans: systematic review. Probiotics Antimicrob Proteins. 2017;9(2):102-10. https ://doi.org/10.1007/s12602-017-9261-2.

13. James KM, MacDonald KW, Chanyi RM, Cadieux PA, Burton JP. Inhibition of Candida albicans biofilm formation and modulation of gene expression by probiotic cells and supernatant. J Med Microbiol. 2016;65(4):32836. https://doi.org/10.1099/jmm.0.000226.

14. Cavalcanti YW, Wilson M, Lewis M, Del-Bel-Cury AA, da Silva WJ, Williams DW. Modulation of Candida albicans virulence by bacterial biofilms on titanium surfaces. Biofouling. 2016;32(2):123-34. https://doi. org/10.1080/08927014.2015.1125472.

15. Sampaio AA, Souza SE, Ricomini-Filho AP, Del Bel Cury AA, Cavalcanti YW, Cury JA. Candida albicans increases dentine demineralization provoked by Streptococcus mutans biofilm. Caries Res. 2019;53(3):322-31. https:// doi.org/10.1159/000494033.

16. Weerasekera MM, Wijesinghe GK, Jayarathna TA, et al. Culture media profoundly affect Candida albicans and Candida tropicalis growth, adhesion and biofilm development. Mem Inst Oswaldo Cruz. 2016;111(11):697702. https://doi.org/10.1590/0074-02760160294.

17. Carlsson J. Nutritional requirements of Streptococcus salivarius. J Gen Microbiol. 1971;67(1):69-76. https://doi.org/10.1099/00221287-67-1-69.

18. Amaechi BT, Higham SM, Edgar WM. Techniques for the production of dental eroded lesions in vitro. J Oral Rehabil. 1999;26(2):97-102.

19. Martins ML, Leite KLF, Pacheco-Filho EF, Pereira AFM, Romanos MTV, Maia LC, Fonseca-Gonçalves A, Padilha WWN, Cavalcanti YW. Efficacy of red propolis hydro-alcoholic extract in controlling Streptococcus mutans biofilm build-up and dental enamel demineralization. Arch Oral Biol. 2018. https://doi.org/10.1016/j.archoralbio.2018.05.017.

20. Martorano-Fernandes L, Cavalcanti YW, de Almeida LFD. Inhibitory effect of Brazilian red propolis on Candida biofilms developed on titanium surfaces. BMC Complement Med Ther. 2020;20(1):104. https://doi. org/10.1186/s12906-020-02893-9.

21. Chevalier M, Ranque S, Prêcheur I. Oral fungal-bacterial biofilm models in vitro: a review. Med Mycol. 2018;56(6):653-67. https://doi.org/10.1093/ mmy/myx 111 .

22. Chen N, Zheng S. Application research of protein test by using biuret reagent. Zhongguo Yi Liao Qi Xie Za Zhi. 2014;38(6):458-60.

23. Alrabiah M, Alshagroud RS, Alsahhaf A, Almojaly SA, Abduljabbar T, Javed F. Presence of Candida species in the subgingival oral biofilm of patients with peri-implantitis. Clin Implant Dent Relat Res. 2019;21(4):781-5. https ://doi.org/10.1111/cid.12760.

24. Heitz-Mayfield LJA, Salvi GE. Peri-implant mucositis. J Periodontol. 2018;89(Suppl 1):S257-66. https://doi.org/10.1002/JPER.16-0488.
25. Mombelli A, Décaillet F. The characteristics of biofilms in peri-implant disease. J Clin Periodontol. 2011;38(Suppl 11):203-13. https://doi. org/10.1111/j.1600-051X.2010.01666.x.

26. Nair RG, Samaranayake LP. The effect of oral commensal bacteria on candidal adhesion to denture acrylic surfaces. An in vitro study. APMIS. 1996a;104(5):339-49. https://doi.org/10.1111/j.1699-0463.1996.tb00725.x.

27. Nair RG, Samaranayake LP. The effect of oral commensal bacteria on candidal adhesion to human buccal epithelial cells in vitro. J Med Microbiol. 1996b:45(3):179-85. https://doi.org/10.1099/00222615-45-3-179.

28. Nair RG, Anil S, Samaranayake LP. The effect of oral bacteria on Candida albicans germ-tube formation. APMIS. 2001;109(2):147-54. https://doi. org/10.1034/j.1600-0463.2001.d01-116.x.

29. de Miranda CM, van Wyk CW, Basson NJ. Growth interaction between Candida albicans and Streptococcus salivarius: in vitro and in vivo studies. J Dent Assoc S Afr. 1992;47(6):253-6.

30. Abranches J, Zeng L, Kajfasz JK, et al. Biology of oral streptococci. Microbiol Spectr. 2018. https://doi.org/10.1128/microbiolspec.GPP3-0042-2018.

31. Kucharíková S, Tournu H, Lagrou K, Van Dijck P, Bujdáková H. Detailed comparison of Candida albicans and Candida glabrata biofilms under different conditions and their susceptibility to caspofungin and anidulafungin. J Med Microbiol. 2011;60(Pt 9):1261-9. https://doi.org/10.1099/ jmm.0.032037-0.

32. Wall G, Montelongo-Jauregui D, Vidal Bonifacio B, Lopez-Ribot JL, Uppuluri P. Candida albicans biofilm growth and dispersal: contributions to pathogenesis. Curr Opin Microbiol. 2019;52:1-6. https://doi.org/10.1016/j. mib.2019.04.001.

33. Hwang G, Marsh G, Gao L, Waugh R, Koo H. Binding force dynamics of Streptococcus mutans-glucosyltransferase B to Candida albicans. J Dent Res. 2015;94(9):1310-8.

34. Xu H, Jenkinson HF, Dongari-Bagtzoglou A. Innocent until proven guilty: mechanisms and roles of Streptococcus-Candida interactions in oral health and disease. Mol Oral Microbiol. 2014;29(3):99-116.

35. Koo H, Andes DR, Krysan DJ. Candida-streptococcal interactions in biofilm-associated oral diseases. PLoS Pathog. 2018;14(12):e1007342. https://doi.org/10.1371/journal.ppat.1007342.

36. Wescombe PA, Heng NC, Burton JP, Chilcott CN, Tagg JR. Streptococcal bacteriocins and the case for Streptococcus salivarius as model oral probiotics. Future Microbiol. 2009;4(7):819-35. https://doi.org/10.2217/ fmb.09.61.

37. Tagg JR, Dajani AS, Wannamaker LW. Bacteriocins of gram-positive bacteria. Bacteriol Rev. 1976;40:722-56.

38. Dempster RP, Tagg JR. The production of bacteriocin-like substances by the oral bacterium Streptococcus salivarius. Arch Oral Biol. 1982;27(2):1517. https://doi.org/10.1016/0003-9969(82)90136-4.

39. Solano C, Echeverz M, Lasa I. Biofilm dispersion and quorum sensing. Curr Opin Microbiol. 2014;18:96-104. https://doi.org/10.1016/j. mib.2014.02.008.

40. Gulati M, Nobile CJ. Candida albicans biofilms: development, regulation, and molecular mechanisms. Microbes Infect. 2016;18(5):310-21. https:// doi.org/10.1016/j.micinf.2016.01.002.

41. Pierce CG, Vila T, Romo JA, Montelongo-Jauregui D, Wall G, Ramasubramanian A, Lopez-Ribot JL. The Candida albicans biofilm matrix: composition, structure and function. J Fungi (Basel). 2017:3:1.

42. Noble SM, Gianetti BA, Witchley JN. Candida albicans cell-type switching and functional plasticity in the mammalian host. Nat Rev Microbiol. 2017;15(2):96-108. https://doi.org/10.1038/nrmicro.2016.157.

43. Calderone RA, Fonzi WA. Virulence factors of Candida albicans. Trends Microbiol. 2001;9(7):327-35. https://doi.org/10.1016/s0966 $-842 \times(01) 02094-7$.

\section{Publisher's Note}

Springer Nature remains neutral with regard to jurisdictional claims in published maps and institutional affiliations. 